\title{
Documentation of Urn Graves of Knovíz Culture by RPAS
}

\author{
Jaroslav Šedina, Eliška Housarová and Eva Matoušková \\ Laboratory of Photogrammetry, Department of Geomatics, \\ Czech Technical University in Prague \\ Thákurova 7, 16629 Prague 6, Czech Republic \\ jaroslav.sedina@fsv.cvut.cz \\ eliska.housarova@fsv.cvut.cz \\ eva.matouskova@fsv.cvut.cz
}

\begin{abstract}
This paper deals with the documentation, positional determination of urn graves of the Knoviz culture (1200-1000 BC), and geometric and positional determination of tumulus at the archaeological site located near the village Ctinèves, in the Usti region in the Czech Republic. Several hundred urn graves are located in the archaeological site and it is one of the biggest burial sites of Knoviz culture in the Czech Republic. RPAS (Remotely Piloted Aircraft System) was used for the documentation and positional determination of urn graves and tumulus. RPAS was equipped by visible spectral range, two near-infrared range, multispectral and thermal camera (one camera for a single flight). The result is a unique data set documenting this archaeological site. Thanks to the suitable winter and spring conditions in 2016 urn graves and tumulus could be detected on the basis of vegetation symptoms. The paper is also focused on how to process the data and creation of a differential digital surface model.
\end{abstract}

Keywords: archaeological survey; digital surface model; differential digital surface model; photogrammetry; orthophoto; RPAS.

\section{Introduction}

RPAS (Remotely Piloted Aircraft System), UAV (Unmanned Aerial Vehicle) or UAS (Unmanned Aircraft System) are growing in importance due to their versatility in the U.S. Nowadays, for control and piloting, RPAS are equipped with sophisticated micro-instruments such as IMU, gyroscopes, GNSS receivers, wireless image insights, wireless controls, automatic stabilization, flight planners, etc. RPAS can provide not only photographic data, but also other data types like multispectral (with NDVI capability) or thermal data too (depending on sensors and type) $[8,2]$. Bigger RPAS are capable of carrying much more expensive and more accurate devices such as laser scanners, hyperspectral cameras and accurate GNSS receivers [4]. The RPAS method of acquisition combines the benefits of close range and aerial photogrammetry [3]. RPAS can be used in many areas, such as archaeological surveying [2, 11], precision agriculture [13], and mapping [10, 7].

RPAS has great benefit for archaeology, documentation of monuments and culture heritage. It is able to carry a variety of sensing devices, it is a versatile instrument, it is capable of very detail imaging of objects and image GSD (Ground Sampling Distance) is in order of cm. This is related to the possibility of creating a digital surface model (DSM) in the order of 
several cm, or in units of dm. For comparison Land Survey Office offers Digital Terrain Model of the Czech Republic of the 5th generation with density of 1.6 points per meter. Another benefit of RPAS is a possibility of thermal imaging due to miniaturization of thermal sensors. Thermal cameras are able to detect subsurface structures to a depth of several $\mathrm{cm}$ or $\mathrm{dm}$. For the detection of subsurface structures it is determined diurnal variation of thermal values [2]. RPAS are also widely used for a photogrammetric documentation of objects and together with terrestrial imaging we are capable of creating complex photogrammetric documentation [11, 1]. Furthermore, RPAS are used along with laser scanning and terrestrial photogrammetry to create comprehensive documentation of archaeological sites and objects [9, 6]. Equally interesting application of RPAS in archaeology is the documentation of the procedure of digs $[12]$.

\section{Archaeological site and subjects of documentation}

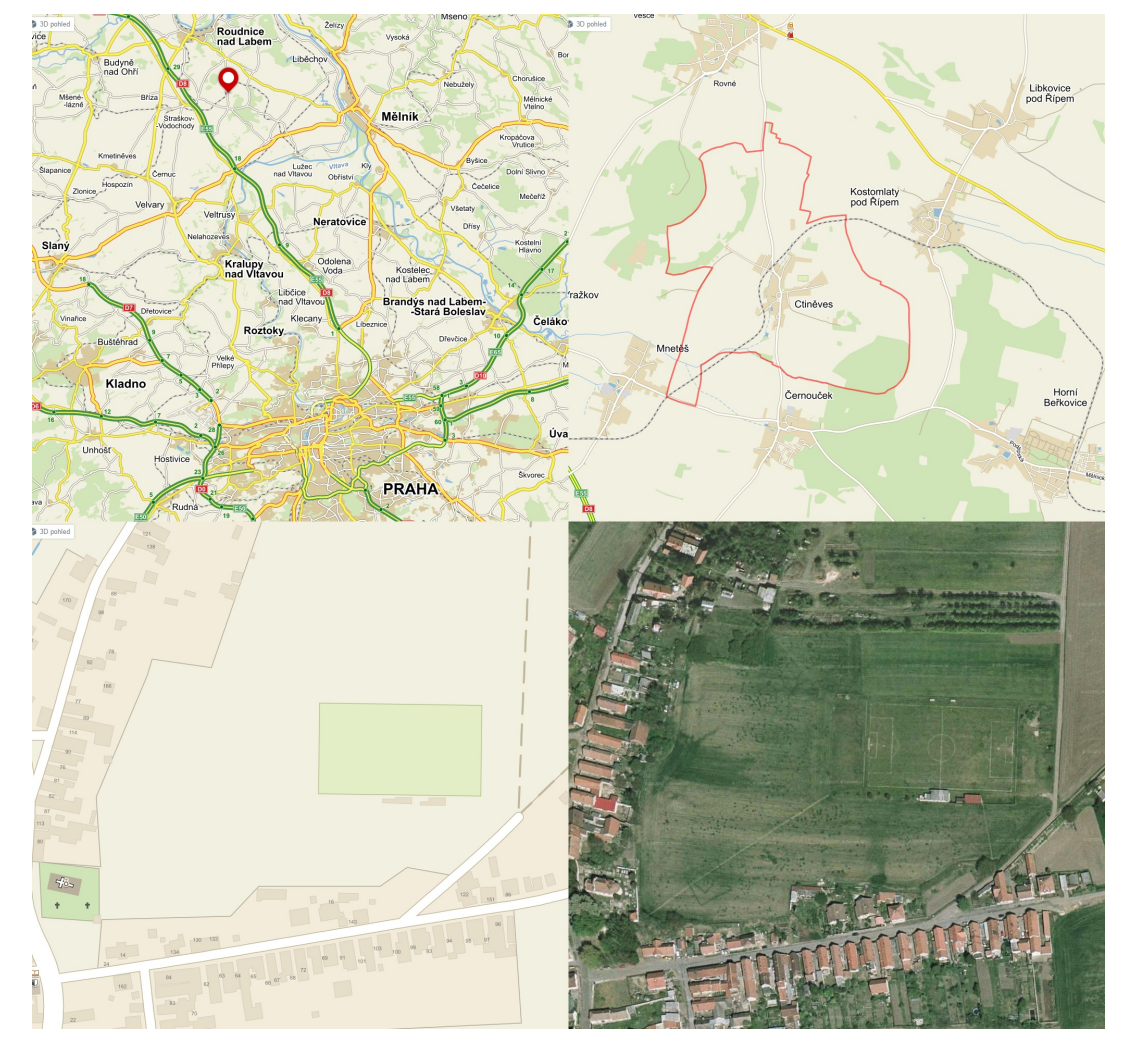

Figure 1: Archaeological site.

The archaeological site is located near the village Ctiněves, in the Usti region in the Czech Republic and is shown in Figure 1. The survey was conducted by prof. Dr. Ing. Karel Pavelka and Ing. Jaroslav Šedina from the Department of Geomatics, Faculty of Civil Engineering, Czech Technical University in Prague and in collaboration with prof. PhDr. Martin Gojda, $\mathrm{PhD}$. from the Department of Archaeology, Faculty of Arts, University of West Bohemia in Pilsen. The subjects of the survey and documentation are tumulus and urn graves occurring in the archaeological site. Urn graves were identified from the debris of urns in 1969 by the National Museum archaeologist Dr. Sklenár as the urn graves of Knovíz culture from the period 1200 to $1000 \mathrm{BC}$. Urn grave is circular in shape and deep about $90 \mathrm{~cm}$. Urn graves 
and urns from the Knovíz culture are shown in Figure 2. At the bottom of the urn grave an urn was found with the ashes of the dead. When ploughing using heavy machinery urns have been damaged and ash of ancestors has served as a source of nutrients for plants. It was possible to detect the urn graves due to a vegetation symptoms. The plants are much greater growth there than the plants in their neighbourhood. A warm winter and spring created great conditions for vegetation symptoms in 2016. A sown grain in the site of urn graves was about 15-20 cm higher than any other grain in their neighbourhood of the 16th June 2016. Urn fields of Knovíz culture are usually small, they seldom have a few dozen graves and bigger one has about 100 urn graves. On this archaeological site there are several hundred of urn graves which makes this site extraordinary.

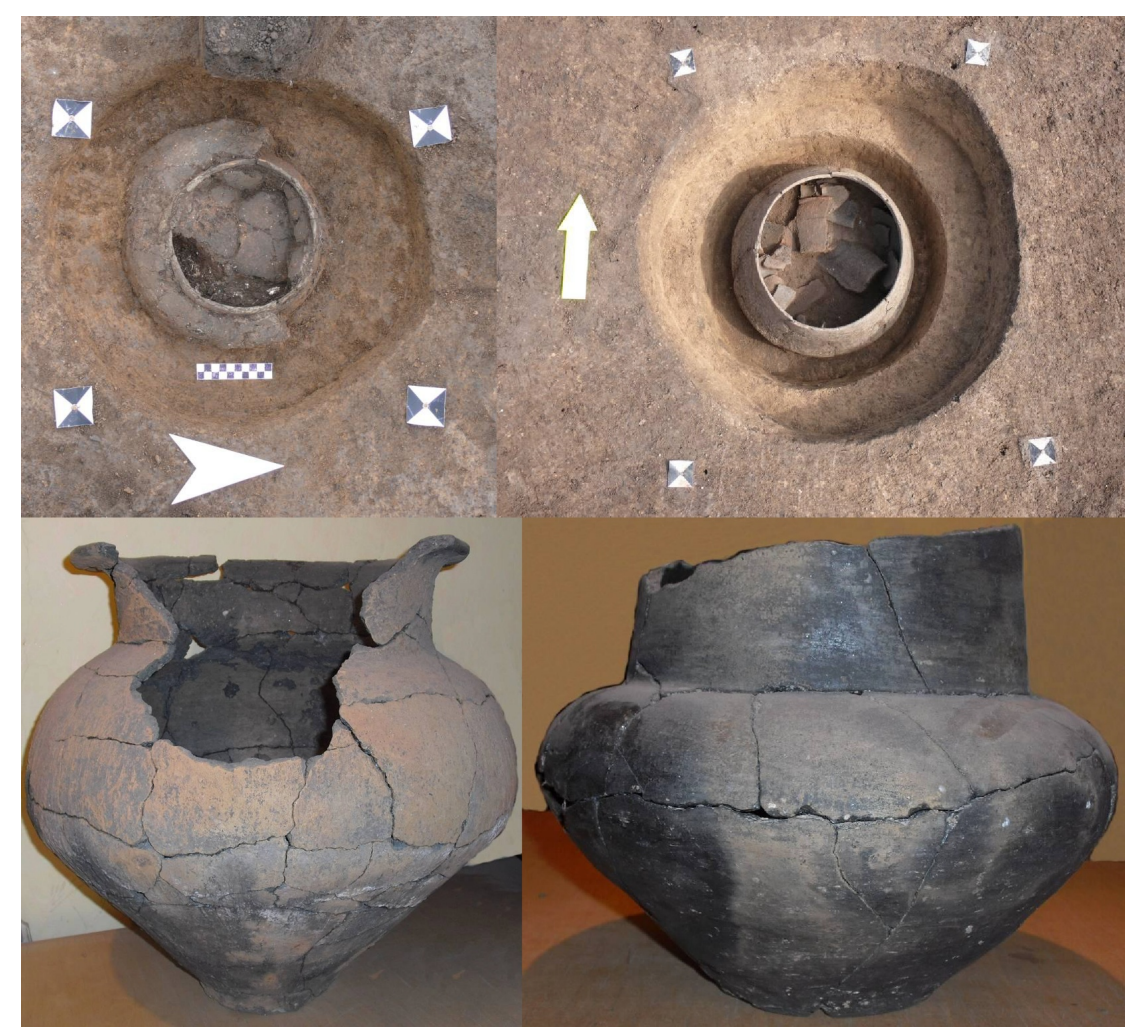

Figure 2: Urn graves and urns [5].

\section{Used technology}

\section{RPAS eBee}

RPAS (Remotely piloted Aircraft System) eBee (see Figure 3) was used for documentation of the position of urn graves and tumulus. RPAS eBee is a wing type and it is a suitable tool for mapping. EBee system consists of several components: the wing, software for planning flight missions and data processing software. EBee enables to program flight over the area with flight time to about 40 minutes. The usage of this RPAS is wide from mapping, orthophoto creation of high-resolution with pixel size around $3 \mathrm{~cm}$, the creation of a DSM (Digital Surface Model) up to monitoring of vegetation condition (e.g. using vegetation index NDVI - Normalized Difference Vegetation Index). 


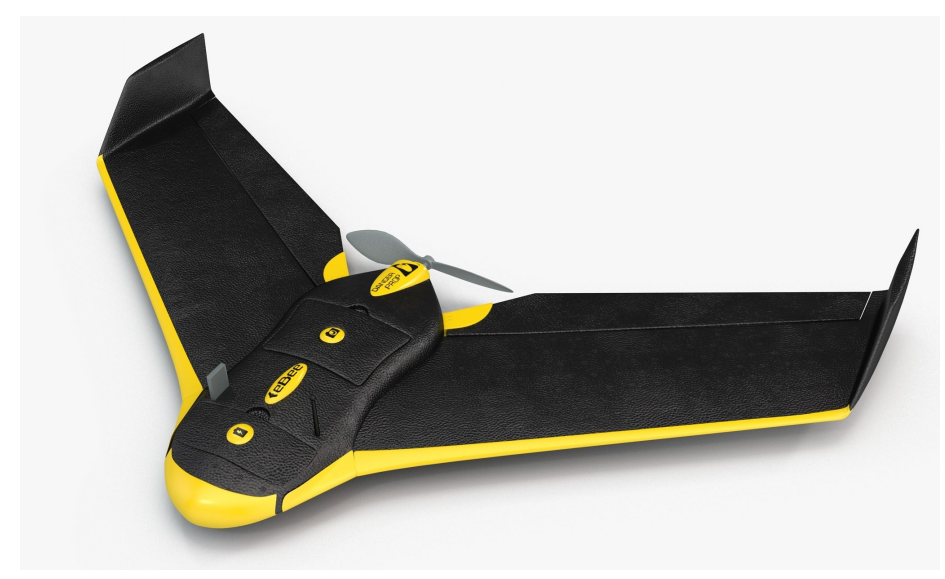

Figure 3: RPAS eBee.

\section{Used cameras}

\section{Canon IXUS 127 HS and Canon PowerShot ELPH 110 HS}

Both cameras have a resolution of $16 \mathrm{Mpx}$ and flight altitude $100 \mathrm{~m}$ AGL (Above Ground Level) corresponds to a GSD of $3 \mathrm{~cm}$. Camera Canon IXUS 127 HS captures the bands RGB - Red, Blue, Green and Camera Canon PowerShot ELPH 110 HS captures the bands NIRGB - NIR (near-infrared), Green, Blue. The cameras belong to the basic equipment of eBee and combining images from both cameras we can perform some tasks remote sensing.

\section{Canon PowerShot S110}

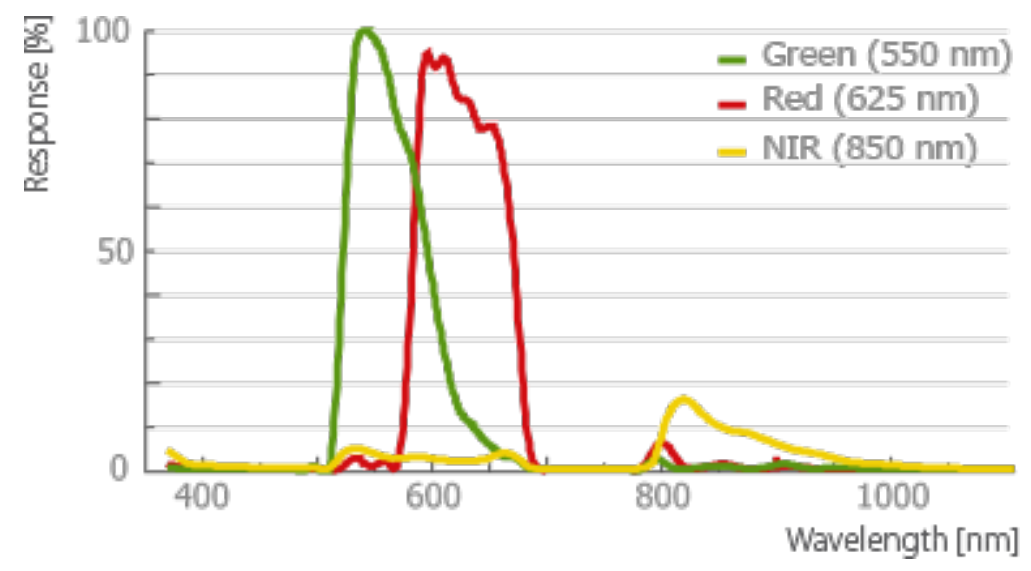

Figure 4: Canon PowerShot S110 bands.

Camera canon S110 is designed for using in precision agriculture and for monitoring and analysis of vegetation cover. The camera captures data in bands NIRRG - NIR, Red and Green as shown in Figure 4. The camera is capable of detailed imaging and an altitude 100 m AGL corresponds to a GSD of $3.5 \mathrm{~cm}$. 


\section{multiSPEC $4 \mathrm{C}$}

Camera multiSPEC 4C provides data in four bands NIRRERG - NIR, Red Edge, Red and Green. It is thus an appropriate tool for the analysis of vegetation and for use in precision agriculture. GSD at altitude $100 \mathrm{~m}$ AGL is about $10 \mathrm{~cm}$. Figure 5 shows spectral bands of four channels of camera multiSPEC $4 \mathrm{C}$.

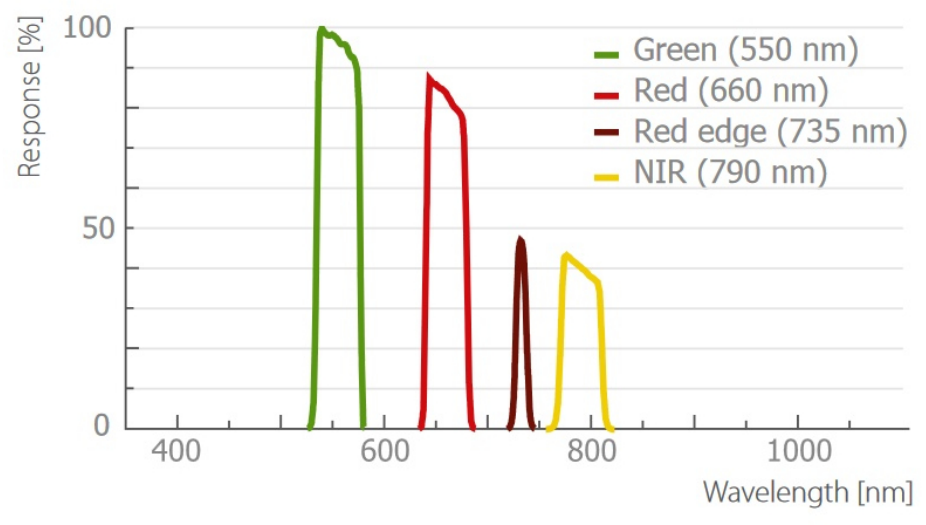

Figure 5: Bands of multiSPEC 4C camera.

\section{thermoMAP}

Thermal camera thermoMAP allows to capture thermal video or thermal images in order to create a thermal map of area. The camera extends the capabilities of the entire eBee system, e.g. for remote sensing, archaeological survey and so on. GSD is approximately $18 \mathrm{~cm}$ for altitude $100 \mathrm{~m}$ AGL. Band response of thermoMAP is shown in Figure 6.

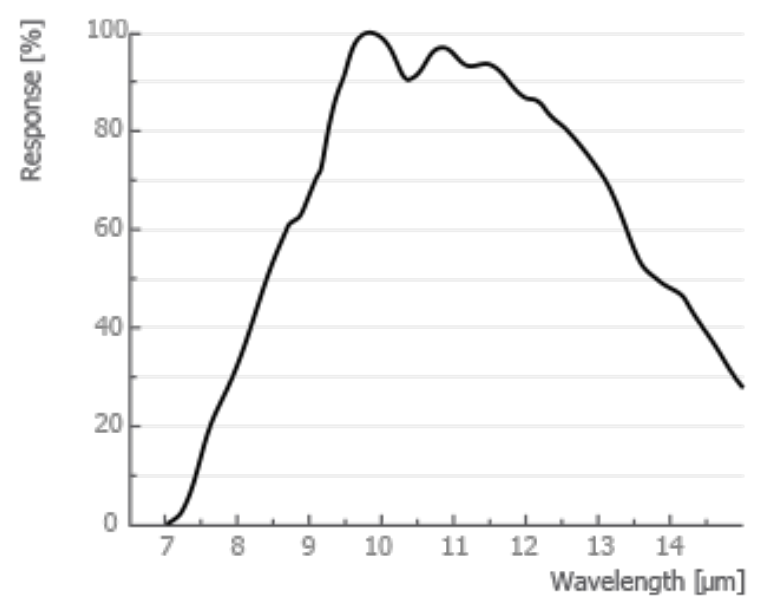

Figure 6: Band response of thermoMAP.

The archaeological site was imaging without using GCPs (Ground Control Points). Imaging took place on the 16th June 2016 in sunny weather. But imaging of the archaeological site had to be interrupted for about an hour because of the occurrence of rain. Immediately after the rain thermal imaging was done. Flight plan for camera Canon IXUS 127 HS over the 


\section{J. Šedina et al. Documentation of Urn Graves of Knovíz Culture by RPAS.}

archaeological site is shown in Figure 7. Table 1 shows the number of images taken with the cameras, sidelaps and overlaps and chosen GSD of images. Thermal camera thermoMAP was imaging in short time intervals with a large overlaps (this way of imaging is recommended by the manufacturer).

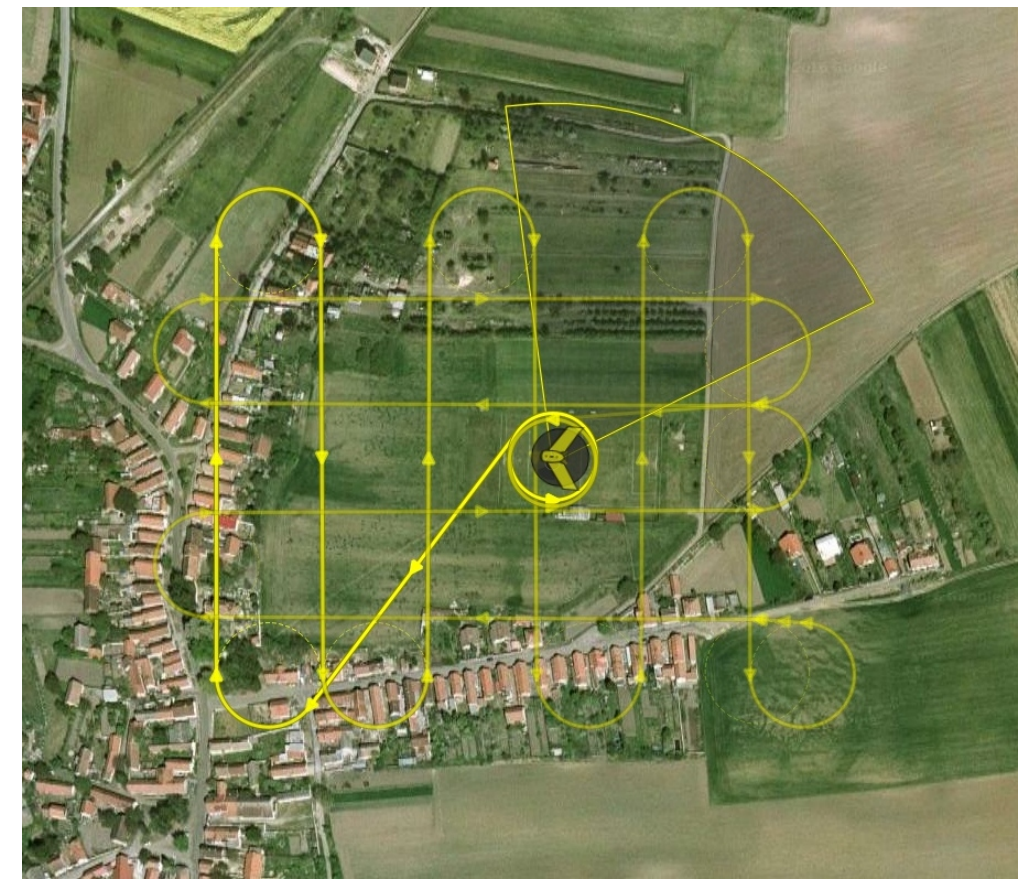

Figure 7: Flight plan over the archaeological site.

Table 1: Parameters of flights.

\begin{tabular}{|c|c|c|c|c|c|c|}
\hline \multirow{2}{*}{ Used camera } & \multicolumn{2}{|c|}{ Number of images } & \multicolumn{2}{|c|}{ Overlaps of images } & GSD & Altitude \\
\cline { 2 - 5 }$[\mathrm{cm}]$ & Straight & Perpendicular & Overlap [\%] & Sidelap [\%] & {$[\mathrm{cm}]$} \\
\hline Canon IXUS 127 HS & 24 & 30 & 60 & 60 & 4 & 130 \\
\hline Canon ELPH 110 HS & 24 & 30 & 60 & 60 & 4 & 130 \\
\hline Canon S110 NIR & 33 & 30 & 60 & 60 & 4 & 115 \\
\hline multiSPEC 4C & 81 & 81 & 60 & 60 & 10 & 96 \\
\hline thermoMAP & 1128 & 1231 & 60 & 60 & 15 & 80 \\
\hline
\end{tabular}

\section{Data processing}

The images captured by cameras Canon IXUS 127 HS, Canon PowerShot ELPH 110 HS and Canon PowerShot S110 were processed together in software Agisoft PhotoScan Pro 1.2.4. The outputs are three orthophotos of the archaeological site with a resolution of $4 \mathrm{~cm} / \mathrm{px}$ and a raster DSM of site with a resolution of $8 \mathrm{~cm} / \mathrm{px}$. DSM and orthophotos have been exported to the coordinate system of UTM zone 33N (EPSG 32633). Images taken with a multispectral camera multiSPEC $4 \mathrm{C}$ and images captured by a thermal camera thermoMAP were processed in software Pix4Dmapper Pro 3.0.3. The output is a thermal orthophoto with a resolution $16 \mathrm{~cm} / \mathrm{px}$ and four orthophotos (for each band) from multispectral camera with a resolution $11 \mathrm{~cm} / \mathrm{px}$. 


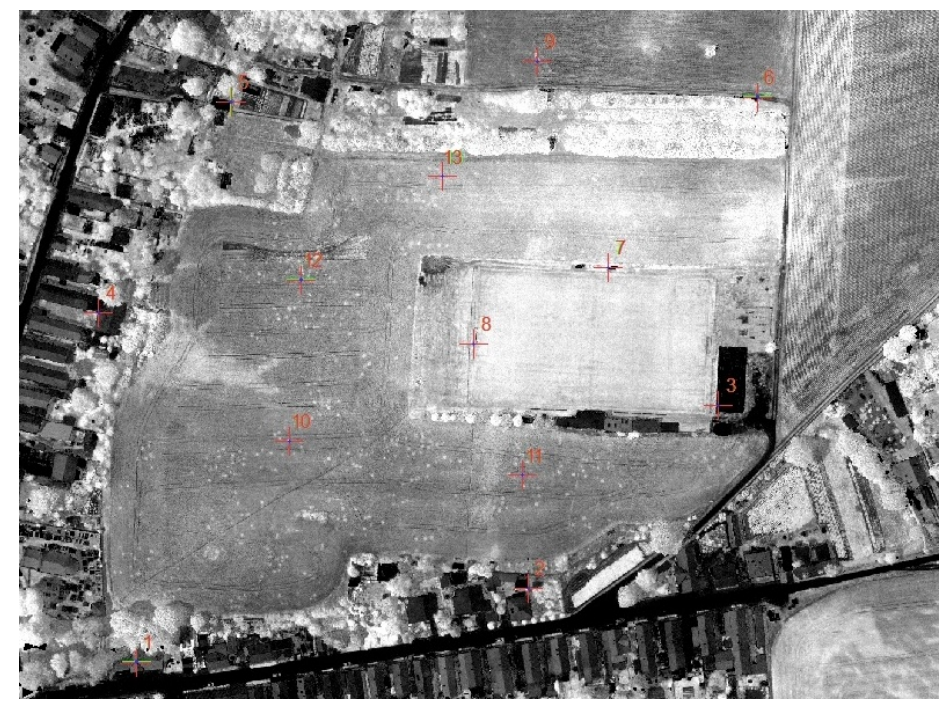

Figure 8: Identical point placement in the site.

Orthophotos were georeferenced together in software ArcGIS 10.2. Orthophoto created in software Agisoft PhotoScan Pro served as a fixed model. Thermal and multispectral orthophotos were georeferenced to 10 identical points, their placement is shown in Figure 8. 1st Order Polynomial Transformation (Affine transformation) was used for georeferencing with Total RMS Error less than $17 \mathrm{~cm}$.

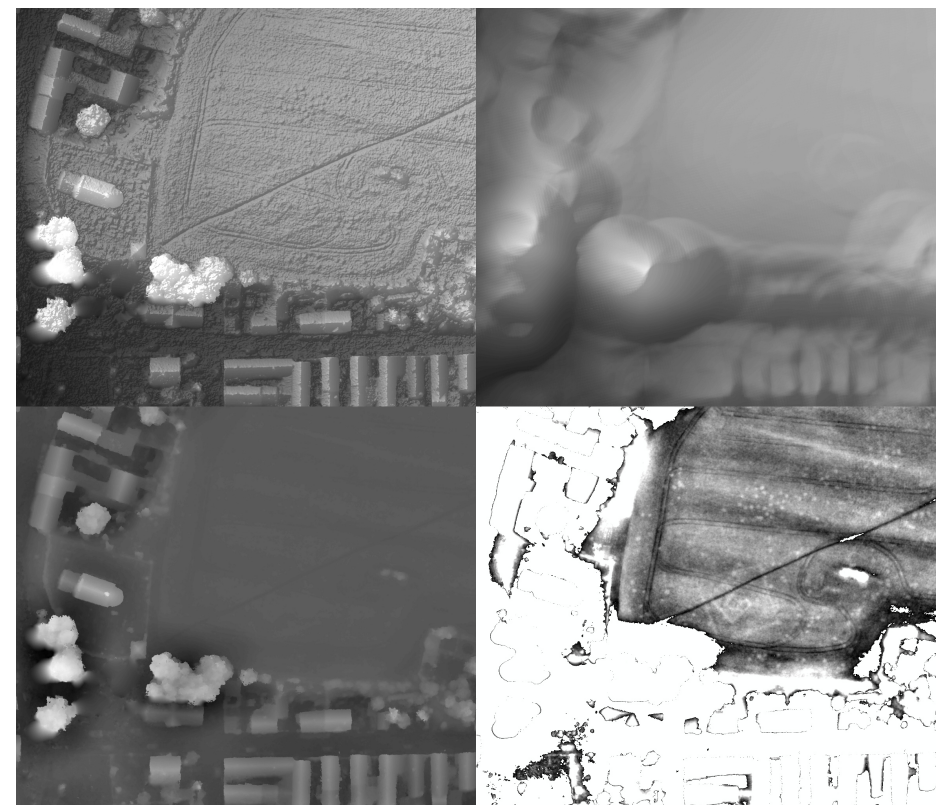

Figure 9: Differential DSM creation.

Moreover a differential DSM was created in software ArcGIS. A function Focal Statistics (Spatial Analyst Tools - Neighbourhood) was used for DSM smoothing with a circular mask of 200 pixels radius. The differential DSM highlights urn graves and tumulus, as shown in Figure 9. Figure 9 top left shows the DSM, top right shows the smoothed DSM, bottom left 


\section{J. Šedina et al. Documentation of Urn Graves of Knovíz Culture by RPAS.}

shows the differential DSM and the bottom right shows the differential DSM with a height restriction to $\pm 0.4 \mathrm{~m}$, which very well highlights urn graves and tumulus.

Furthermore, in ArcGIS software were created orthophotos NIR - Red (Red band was subtracted from the NIR band). This type of orthophoto was created for the NIR camera Canon PowerShot S110 and for the multispectral camera multiSPEC 4C. Figure 10 shows a process of highlighting urn graves and tumulus on the archaeological site for the camera multiSPEC 4C. Figure 10 on the top left shows NIR band orthophoto, on the top right is the Red band orthophoto, on the bottom left is the orthophoto NIR - Red and on the bottom right is shown highlighted orthophoto NIR - Red.

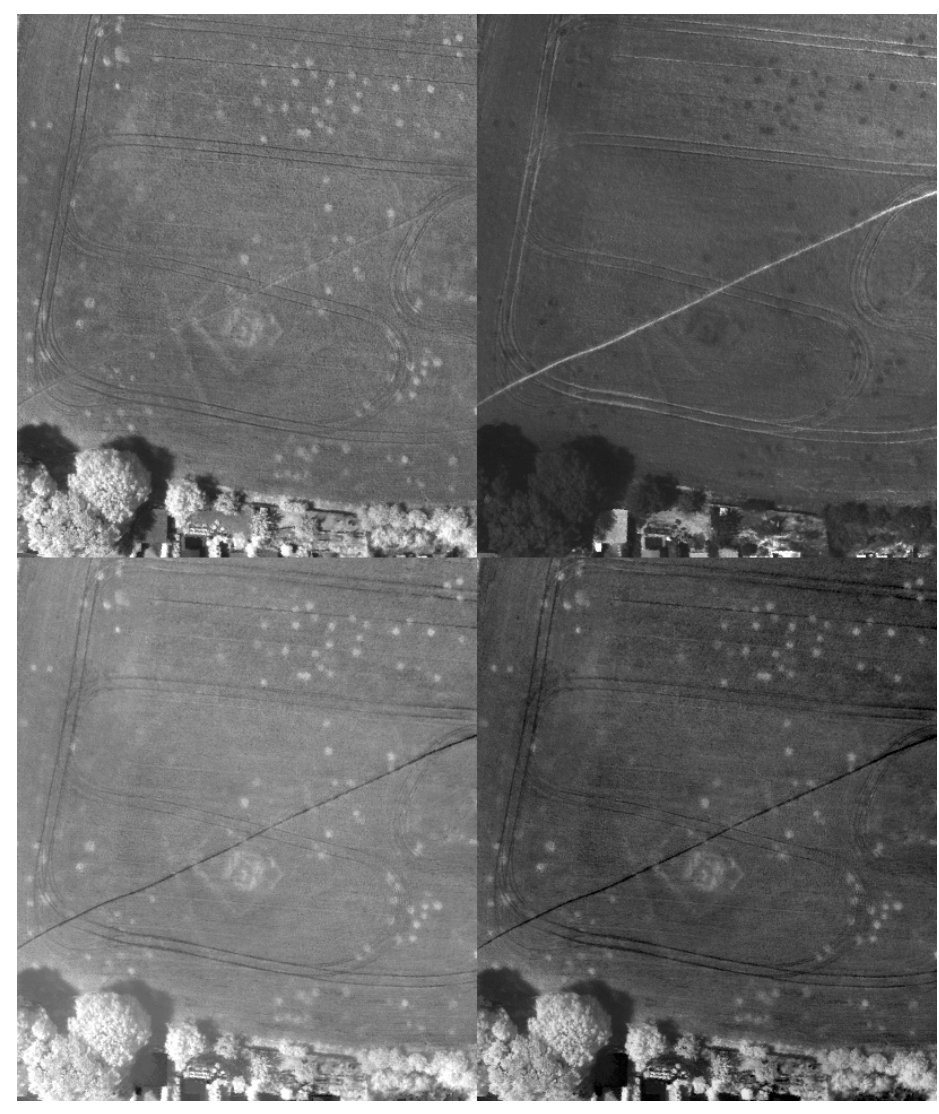

Figure 10: Creation of NIR - Red orthophotos.

\section{Outputs}

The project result is a set of thematic maps documenting archaeological site and vector drawing showing the location of the urn graves and the shape and position of the tumulus. Altogether there was found 510 urn graves in the archaeological site, which makes the place one of the biggest archaeological sites of urn graves of Knovíz culture. Maps are created in the coordinate system S-JTSK (EPSG 5514, S-JTSK Krovak EastNorth):

- Orthophoto VIS (RGB) - Canon IXUS 127 HS images

- Orthophoto NIR (NIRGB) - Canon PowerShot ELPH 110 HS images 
- Orthophoto NIR (NIRRG) - Canon PowerShot S110 images

- Thermal map - thermoMAP images

- Orthophoto NIR - Red S110 - Canon PowerShot S110 images

- Orthophoto NIR - Red multiSPEC 4C - multiSPEC 4C images

- Digital Surface Model - Canon IXUS 127 HS, Canon PowerShot ELPH 110 HS, Canon PowerShot S110 images

- Differential Digital Surface Model

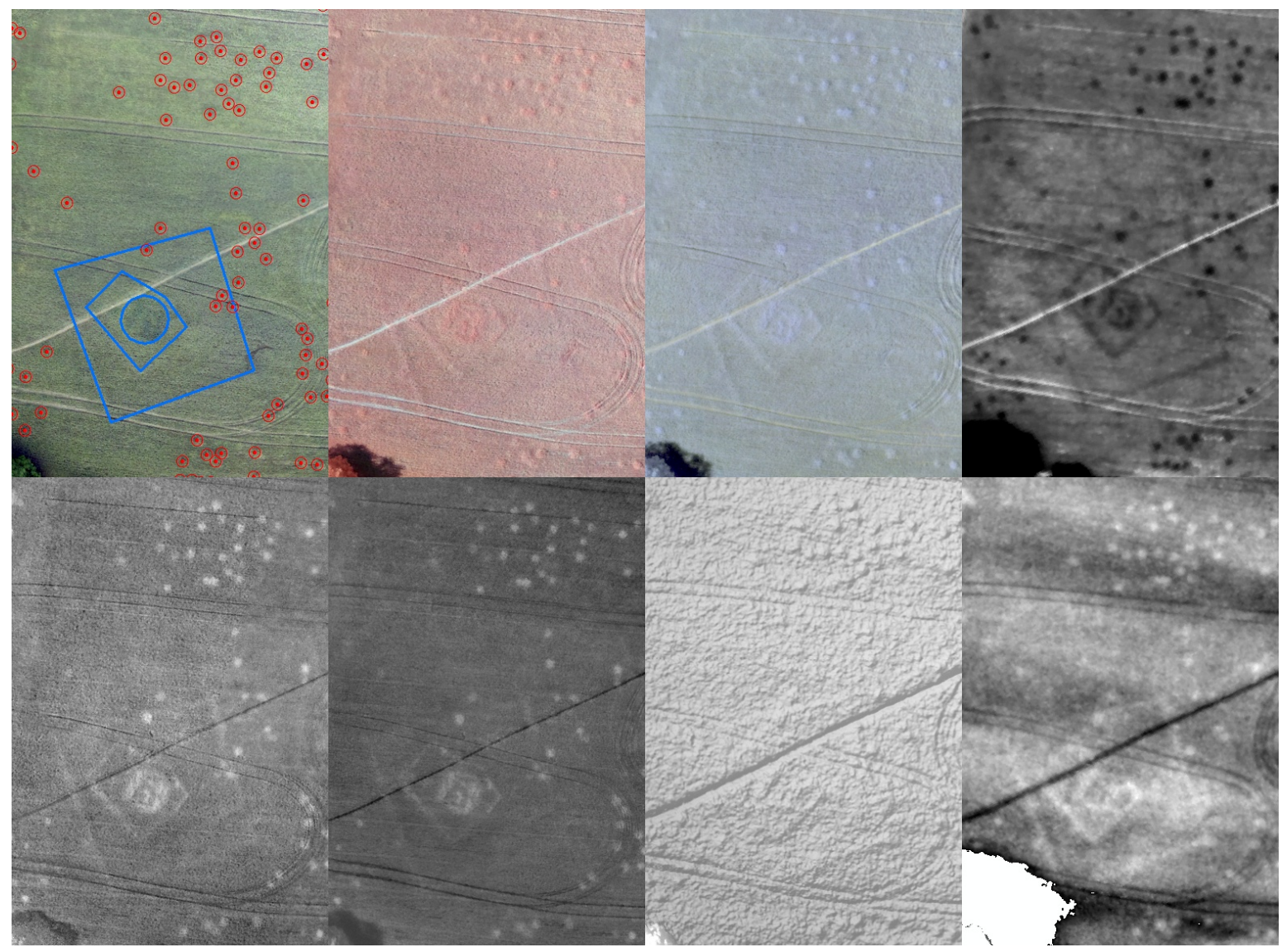

Figure 11: Comparison of the outputs.

Figure 11 shows the outputs, from the top left is shown an orthophoto (RGB), NIR (NIRGB), NIR (NIRRG), thermal map, from the top left is shown an orthophoto NIR - Red S110, NIR - Red multiSPEC 4C, Digital Surface Model and Differential Digital Surface Model. Figure 11 shows that urn graves and tumulus excel at Orthophoto NIR - Red S110 and Orthophoto NIR - Red multiSPEC 4C and they are well visible in the Differential Digital Surface Model and in the Thermal map. In the Thermal map there are urn graves and tumulus much more visible and it has greater contrast with its surroundings than in other outputs. The tumulus and urn graves are also well visible in the Differential Digital Surface Model. 


\section{J. Šedina et al. Documentation of Urn Graves of Knovíz Culture by RPAS.}

\section{Conclusion}

In the archaeological site near the Ctiněves village there were found over 500 urn graves of Knovíz culture and it is one of the biggest sites located on the territory of the Czech Republic. RPAS eBee was used for documentation of the archaeological site. Five flights were performed, each using a different camera - VIS, NIR, NIR, multispectral and thermal camera. This gave rise to several orthophotos and a DSM. Furthermore a differential DSM was created in software ArcGIS. Outputs serve for the documentation and for the positional determination of individual urn graves and for the geometric and positional determination of tumulus at the archaeological site. Documentation and positional determination could be made due to vegetation symptoms of urn graves and tumulus. It was caused by favourable conditions for formation of vegetative symptoms during the winter and the spring in the 2016 . Due to these conditions a unique set of data documenting the urn graves of Knovíz culture and tumulus in the archaeological site located near Ctiněves village could be created.

\section{Acknowledgements}

This paper project was supported by a grant of the Ministry of Culture of the Czech Republic NAKI DF13P01OVV002 (New modern non-invasive methods of cultural heritage objects exploration).

\section{References}

[1] M Bolognesi et al. "Testing the low-cost RPAS potential in 3D cultural heritage reconstruction". In: The International Archives of Photogrammetry, Remote Sensing and Spatial Information Sciences 40.5 (2015), p. 229. DOI: 10.5194/isprsarchives-XL-5W4-229-2015.

[2] Jesse Casana et al. "Archaeological aerial thermography: a case study at the Chacoera Blue J community, New Mexico". In: Journal of Archaeological Science 45 (2014), pp. 207-219. DOI: $10.1016 / \mathrm{j} \cdot \mathrm{j}$ as . 2014.02.015.

[3] Henri Eisenbeiß. UAV photogrammetry. Available at http://www.igp-data.ethz.ch/ berichte/Blaue_Berichte_PDF/105.pdf. ETH Zurich, Switzerland, 2009.

[4] Jakub Jon, Bronislav Koska, and Jiří Pospíšil. "Autonomous airship equipped with multi-sensor mapping platform". In: ISPRS-International Archives of the Photogrammetry, Remote Sensing and Spatial Information Sciences XL-5 W 1 (2013), pp. 119124. DOI: 10.5194/isprsarchives-XL-5-W1-119-2013.

[5] Radka Kornelaková. Pohřebiště knovízského okruhu. Available at http://dspace .upce. cz/handle/10195/38449. Bakalářská práce (bachelor's thesis). 2010.

[6] Karsten Lambers et al. "Combining photogrammetry and laser scanning for the recording and modelling of the Late Intermediate Period site of Pinchango Alto, Palpa, Peru". In: Journal of archaeological science 34.10 (2007), pp. 1702-1712. DOI: 10.1016/j . jas . 2006.12 .008$.

[7] M Manyoky et al. "Unmanned aerial vehicle in cadastral applications". In: ISPRSInternational Archives of the Photogrammetry, Remote Sensing and Spatial Information Sciences 3822 (2011), p. 57. DOI: 10.5194/isprsarchives-XXXVIII-1-C22-57-2011. 
[8] K. Pavelka and M. Řehák. "Using of UAV for photogrammetry and thermal imaging". In: Proceedings of ACRS. 2012, pp. 589-601.

[9] Fabio Remondino et al. "Multi-sensor 3D documentation of the Maya site of Copan". In: 22nd CIPA Symposium, Kyoto, Japan. 2009, pp. 131-1. DOI: 10.13140/2.1.2831.3929.

[10] M Rijsdijk et al. "Unmanned Aerial Systems in the process of Juridical Verification of Cadastral Borders". In: Presentation at UAV-g Conference, Rostock University, Rostock, Germany. Available at http: //www. int-arch-photogramm-remote-sensspatial - inf - sci . net / XL - 1 - W2 / 325 / 2013 / isprsarchives - XL - 1 - W2 - 325 2013.pdf. 2013. DOI: 10.5194/isprsarchives-XL-1-W2-325-2013.

[11] Renato Saleri et al. "UAV photogrammetry for archaeological survey: The Theaters area of Pompeii". In: Digital Heritage International Congress (DigitalHeritage), 2013. Vol. 2. IEEE. 2013, pp. 497-502. DOI: 10.1109/DigitalHeritage.2013.6744818.

[12] Martin Sauerbier and Henri Eisenbeiss. "UAVs for the documentation of archaeological excavations". In: International Archives of Photogrammetry, Remote Sensing and Spatial Information Sciences 38.Part 5 (2010), pp. 526-531.

[13] Francisco Agüera Vega et al. "Multi-temporal imaging using an unmanned aerial vehicle for monitoring a sunflower crop". In: Biosystems Engineering 132 (2015), pp. 19-27. DOI: 10.1016/j. biosystemseng. 2015.01.008. 
